\title{
OER in practice: Organisational change by bootstrapping
}

\author{
John Hannon, ${ }^{1}$ Simon Huggard, ${ }^{2}$ Annabel Orchard ${ }^{3}$ and Nick Stone ${ }^{4}$ \\ 1. La Trobe University, Australia | j.hannon@latrobe.edu.au \\ 2. La Trobe University, Australia | s.huggard@latrobe.edu.au \\ 3. Monash University, Australia| annabel.orchard@monash.edu \\ Submitted in: February 2014 \\ Accepted in: April 2014 \\ 4. La Trobe University, Australia|n.stone@latrobe.edu.au \\ Published in: July 2014
}

\section{Recommended citation}

Hannon, J., Huggard, S., Orchard, A. \& Stone, N. (2014). OER in practice: Organisational change by bootstrapping . RUSC. Universities and Knowledge Society Journal, 11(3). pp. 134-150. doi http://dx.doi.org/10.7238/rusc.v1113.2131

\begin{abstract}
In this paper, we investigate an approach to institutional change that aims to establish open educational practices (OEP) in a university and inculcate the use of open education resources (OER) as part of its curriculum work and teaching practice. Traditional practices that involve delivering knowledge resources for individualised learning within semester-length units of study are becoming increasingly ill-adapted to the demands of a dynamic and global educational landscape. OER offers a sustainable and equitable alternative to such closed arrangements, with the potential to meet the emerging demands of distributed learning settings. Nevertheless, changing educational practice remains a formidable challenge, and adopting OER is a radical break from legacy institutional practices. Our focus in this paper is on the starting point for embedding OER in curriculum work and teaching practice. We investigate change through emergent initiatives rather than a top-down program at La Trobe University in Australia: we ask what connections are necessary to establish open practices in a university. We trace three instances of OEP in one university that together build capacity in OER. We draw on Bardini's strategy of bootstrapping, as an iterative and co-adaptive learning process that connects good practices in situ with institutional structures in order to build the groundwork for emergent change. These cases demonstrate how disparate innovations can be connected and re-purposed to establish a network of nascent OEP.
\end{abstract}

\section{Keywords}

open educational resources, open educational practices, sustainable, openness, practice, bootstrapping 


\section{Los REA en la práctica: el cambio organizativo mediante el bootstrapping}

\section{Resumen}

En este trabajo investigamos un planteamiento de cambio institucional encaminado a establecer prácticas educativas abiertas (PEA) en una universidad e inculcar el uso de recursos educativos abiertos (REA) como parte de su trabajo curricular y su práctica educativa. Las prácticas tradicionales, consistentes en proporcionar recursos de aprendizaje para una enseñanza individualizada en módulos académicos semestrales, se adaptan cada vez peor a los requisitos de un panorama educativo dinámico y global. Los REA ofrecen una alternativa sostenible y equitativa a estas prácticas cerradas, y tienen la capacidad de satisfacer la demanda emergente en entornos de aprendizaje distribuido. No obstante, cambiar las prácticas educativas sigue siendo un reto formidable, y la adopción de los REA supone una ruptura radical con respecto a las prácticas institucionales heredadas. En el presente trabajo nos centramos en el punto de partida para integrar los REA en el trabajo curriculary las prácticas educativas. En la Universidad La Trobe (Australia) investigamos este cambio más a través de iniciativas emergentes que de un programa diseñado jerárquicamente desde arriba: nos planteamos cuáles son las conexiones necesarias para implantar prácticas abiertas en una universidad. Describimos tres casos de PEA que, juntos, generan capacidades de REA en una universidad. Aprovechamos la estrategia de bootstrapping planteada por Bardini como proceso de aprendizaje iterativo y coadaptativo que conecta las buenas prácticas in situ con las estructuras institucionales a fin de sentar las bases de trabajo para el cambio emergente. Estos casos demuestran cómo unos procesos innovadores tan dispares se pueden conectar y modificar para crear una red de PEA incipiente.

\section{Palabras clave}

recursos educativos abiertos, prácticas educativas abiertas, sostenible, carácter abierto, práctica, bootstrapping 


\section{Introduction}

Open educational resources (OER) have emerged as a significant global presence in higher education as a consequence of the rise of networked forms of knowledge and learning. Yet, OER adoption has been "patchy" (McKerlich, Ives, \& McGreal, 2013) or slow (Conole, 2012; Pegler, 2013), despite reports of broad-based and extensive projects over the last decade, for example, the OPAL Report (2011) and Horizon Report (Johnson et al. 2013). Evidence from these OER reports and investigations suggests the critical issue for OER is neither access to resources nor their integration with institutional systems, but practices in teaching and learning and how to engender and support them. The OER literature offers accounts of practice initiatives that flourish where supportive institutional arrangements, strategies and structures exist (for example, a special OER issue in McGreal, Kinuthia, and Marshall (2013) and Conole (2012)). Bossu, Brown, and Bull (2012) surveyed OER in a study of 37 Australian universities and noted the limited and early stage development of OER in Australian higher education, identifying "insufficient institutional support and the lack of institutional policies to address OER developments, as barriers to the growth of the OER movement" (p. 130).

This paper focuses on small initiatives in OER that exemplify the early stage, nascent OER development within Australian higher education, and the initial change process that is necessary in the absence of mature national or cross-institutional OER projects. We examine instances of OER activity at La Trobe University that exemplify the OPAL Report's (2011) recommendation that organisations shift focus from resources to practices, that is, from OER to open educational practices (OEP), by providing a supportive framework and encouraging "cultures of innovation" (p. 56). These initiatives at La Trobe demonstrate local initiatives as an emergent process of organisational change focused on academic teaching practice.

\section{Embedding OEP through institutional change}

Establishing OER as part of institutional academic culture, therefore, will need to do more than focus on resources per se, their dimensions, their conditions of access, and their interoperability (OPAL Report, 2011; Hannon et al., 2013). Arguably, the task of embedding OEP has been underestimated. The uses of OER offer a significant departure from traditional modes of higher education that embody regimes of individualised learning and lecture-based pedagogies in which learning is contained within institutional boundaries (Weller, 2011; Neary \& Winn, 2009). Yet these traditional modes and their entrenched institutional networks present formidable challenges to change. While these challenges may be framed as issues of integration, or sustainable cost models (Wiley \& Gurrell, 2009), perhaps more challenging is the institutional momentum that arises from "business as usual" approaches; the default implementation of learning technology systems that replicate the transmissive, teacher-centred learning of lecture-based delivery (Lane, 2009; Hannon, 2013). Indeed, a paradox of e-learning is its reproduction of traditional pedagogies, despite the innovations afforded by Internet connectivity, with the consequence that innovative pedagogies become marginal to the institution (Brown, 2013).

A strategy to embed OEP that is consistent with the OPAL Report recommendations is articulated by Gunn (2014), who identifies the uncertainty and potential invisibility of useful innovations. She proposed a change process that supported "cultures of innovation" (p. 396) through a "productive partnership" between innovators and institutions that offer forms of reporting and recognising successful innovative efforts within institutional 
processes. We take up Gunn's "productive partnerships" in the change process, working from local initiatives to ask what connections, negotiations, policies, technologies and procedures are necessary to establish a culture of innovation around OEP.

The cases in this study at La Trobe University occur in the absence of national or cross-institutional OER projects, but in the presence of a supportive university policy for open education licences and development. The absence of external drivers and funding sources sets the conditions for organisational change through bootstrapping.

A bootstrapping approach to change builds on existing initiatives to embed institutional OER through a bottomup process, and can be distinguished from top-down, Rogerian strategies of change (Rogers, 2003) that are unable to scope emergent and local innovations. We draw on Bardini's (2000) reference to Engelbart's "philosophy of 'bootstrapping', in which each experimental transformation of the social-technical system ... would feed back into the system itself, causing it to evolve" (p. 108). Bootstrapping, in this study, is a co-adaptive reciprocal learning process led by innovative practices that establish productive connections with institutional practices. Bootstrapping, then, occurs through productive partnerships between local innovations and organisational systems: vertically through policy, procedures and faculty strategies, and horizontally at the "meso level": academics, educational designers, curriculum, and library systems. The starting point is the shared activities of OEP.

Our aim in this paper is to demonstrate how three local initiatives in OEP can establish innovative connections in a social-technical system, that is, connect disparate parts of the university in order to bootstrap organisational change.

\section{Method}

We adopted a case study approach to three initiatives in embedding OER in the organisation. The value of the case study approach, according to Yin (2009) and Stake (2008), lies not in producing comparative data, but in their applicability to a domain of practice, and in offering their practitioner audience an "opportunity to learn" (Stake, 2008 , p. 130) that is potentially relevant and useful.

Our case studies follow the researcher-practitioner tradition (Schon, 1995), presenting an "insider" account of experiential knowledge from an involved practitioner, yet juxtaposed with the "outsider" perspective in the form of empirical results that ground the cases with some measure of its effects.

The cases describe how three initiatives establish connections with university systems and processes: the university library digital repository; resources located in both iTunes $U$ and as OER; and the community-centred unit of study' Indigenous and Intercultural Health that has simultaneous iterations in the university Learning Management Systems (LMS) and on an open Wikiversity platform. Results on the impact of the cases are included in each account.

1. The term "unit of study" refers to the subjects or courses that make up a university degree program. 


\section{Case studies in emergent practice:}

\section{Case 1: Repurposing the library digital repository for OER}

The digital repository Research Online was established in 2009 at a time when university libraries were funded through the Australian Research Repositories Online to the World (ARROW) initiative, to create open repositories for the dissemination of published research papers and digital theses (Hannon et al., 2013). Through its digital repository, the university library manages scholarly information: It curates and publicises university research outputs to the wider academic community and reports to the Australian Government through the Higher Education Research Data Collection (HERDC) (2014) process. Curating research data is the primary purpose of many university repositories; therefore, the addition of OER content to repositories has not been a priority.

Most universities in Australia select one of two different paths for the creation, management and dissemination of educational resources. Most common is the implementation of an enterprise LMS such as Moodle, Blackboard and Sakai, in which resources for degree programs appear within separate, heterogeneous units of study, with access only for participating teaching staff and students. An alternative path has been the creation of repositories for storing educational resources using commercial software (e.g., Equella). These two developments encouraged coordination of resources for internal use and local common storage, and were not designed for discovery through Google searches from outside the university. Recent moves to open content through Massive Open Online Courses (MOOCs) has been shaped by marketing goals to persuade participants to enrol in degree courses with the university (Wellen, 2013). Resources in systems such as iTunes U, Coursera, Udacity and edX may be open in the sense of "free to try", but with licence restrictions on use and reuse.

Repurposing the repository: In March 2013, significant work on the repository was completed to enable uploading, searching and dissemination of OER. The library modified the existing, back-end storage system, Fedora open source software, and the front-end search and indexing commercial software Valet and Vital, so that OER material in the repository could be quickly delivered through the established systems. The following steps were taken to set up the OER repository software:

1. Creation of an OER submission form (Figure 1) (http://arrow.latrobe.edu.au/valet/submit.cgi?view=OER)

2. Linking of form fields to appropriate metadata terms

3. Implementation of the schema.org and IMS schemas and nomenclature for learning objects

4. Development of a review and management workflow

5. Testing of indexing of ingested objects within Google and limiting searches to OER and Creative Commons licensed material

This repurposing process enabled staff to upload objects into the repository, assign open licensing (Figure 2), search within the interface, and re-use content created by colleagues (Figure 3). As resources are provided to the repository, OEP are put into place.

OER usage of the repository: The Research Online repository contains all of the university's published output for HERDC data collection for the period 2000-2012. This included metadata for over 30,000 published works: book chapters, conference papers, journal articles and artistic works, and includes other material such as websites, working papers and digitised books. The gathering of this full text material occurs mainly through invitation to academics to submit their published works for "open access" in the repository. 


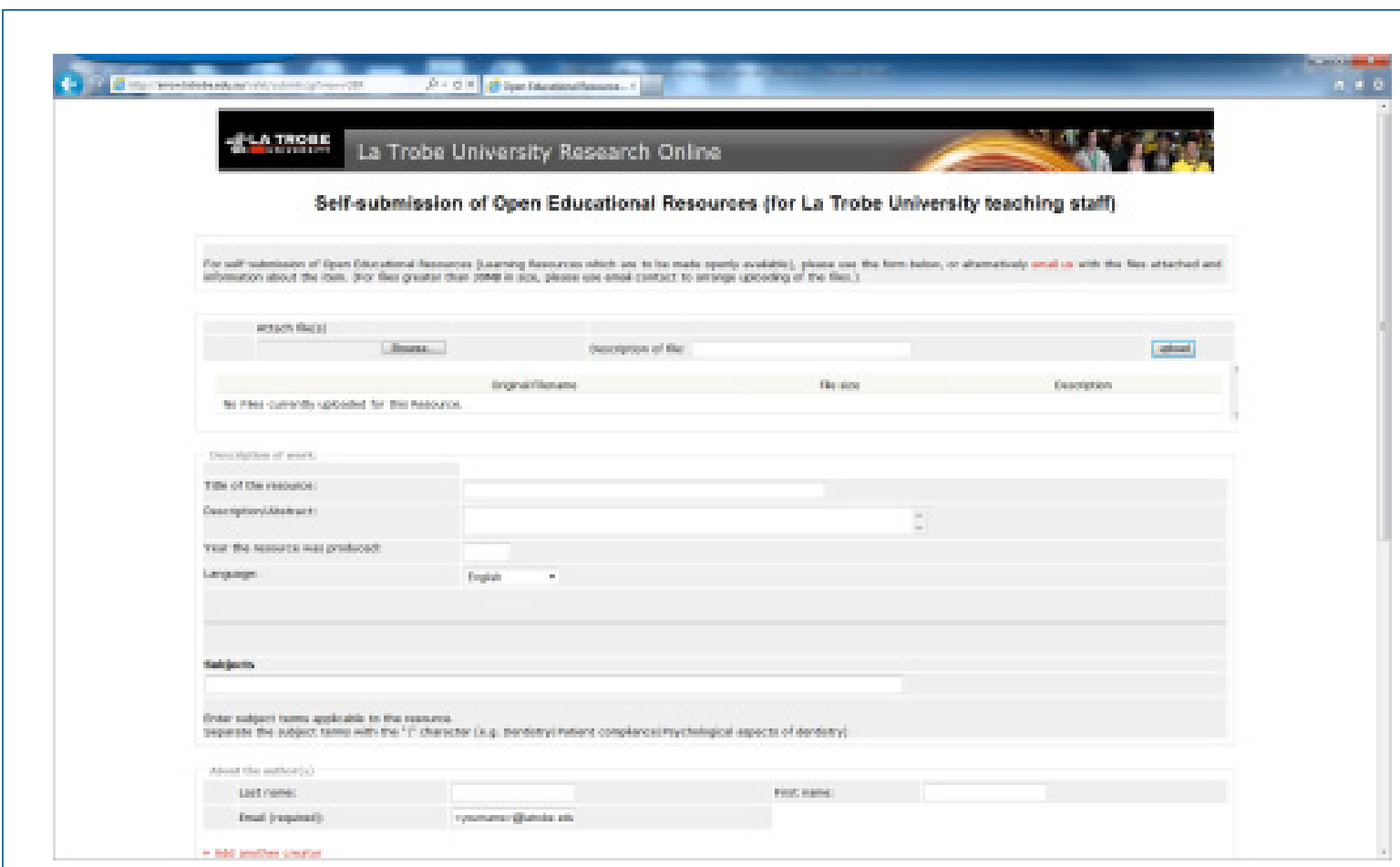

Figure 2. Creative Commons licence options within the form

Ucensing - For an Open Educational Resource a licence must be applied to indicate allowed use and reuse of the material Creative Commons licences are specified here, but other licensing can be instituted upon request -- (the licence icons below Ink to details about each licence):

\section{Crestive Commons Attribution licence}

\section{(6) (†)}

Creative Commons Attribution ShareAlihe licence

\section{(c) (9)}

Crestive Commons Attribution NoDerivs licence

\section{(a) (1) 0}

Creative Commons Attribution Noncemmercial licence

\section{(ㅇ) (1) (2)}

Creative Commons Attribution NonCommencial ShareAlke licence

@OQ9

Creative Commons Mttribution NonCommarcial NoDerivs licence

(ब) 090

This engagement with the academic community, through advocacy and promotion of university authored works, has provided a strong basis for engaging with academics to provide a trusted storage and dissemination environment for OER works in the repository. 
Figure 3. Search and discovery of OER within the digital repository

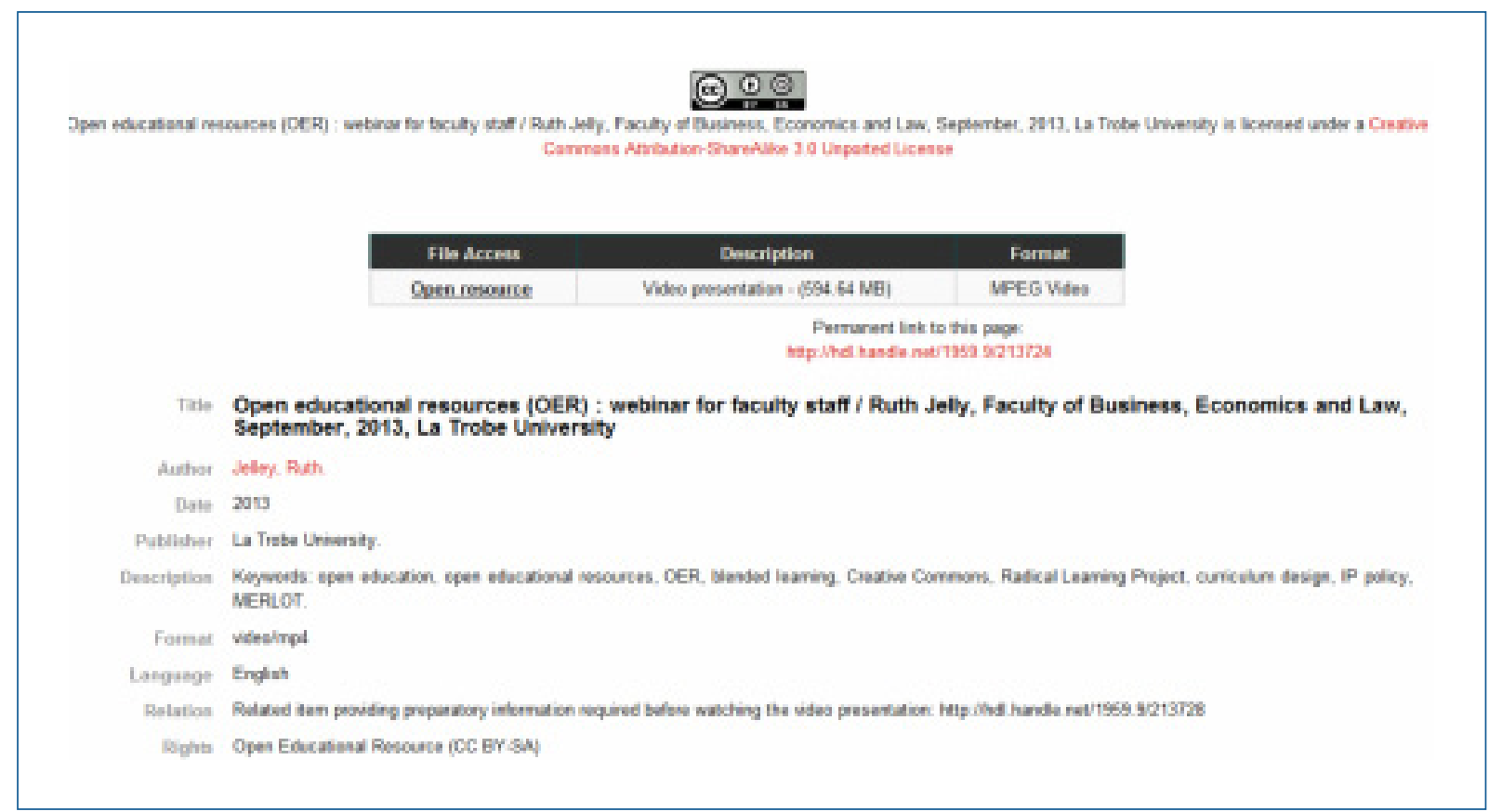

Since 2009, an estimated 500-1,000 academics (30-60\%) have provided the library with copies of research material for the repository, with usage shown in Table 1:

Table 1: Repository usage

\begin{tabular}{|l|c|c|}
\hline \multicolumn{1}{|c|}{ Annual Statistics for the Library } & Year 2012 & 2013 YTD \\
\hline Institutional Repository hits - total & 398,231 & 781,071 \\
\hline Institutional Repository - downloads & 12,889 & 15,112 \\
\hline
\end{tabular}

In addition to research materials, the library has registered interest in OER materials in the repository. Currently, there are a small number of OER items in the repository (about 15). Some examples for different OER items are:

\footnotetext{
110 hits and 149 downloads

32 visitors, 69 hits

82 visitors, 132 hits
}

Uptake of the OER repository at this early stage has been slow for 2013. Nevertheless, the level of academic engagement (Table 2), indicated by the number of open access publications deposited into the repository, shows a positive correlation between repository downloads in Table 1 and numbers of open access items in Table 2.

The data from Table 2 suggests that repurposing the library repository has established a practice of open access in the university. These figures suggest that a university communication strategy is needed to ensure that academics are aware of OER and feel safe about uploading educational resources into the repository. The increase 
in the deposit and use of OER items in the repository also demonstrates the potential for a sustainable OER practice to become embedded in the university, with a strategy of leadership and communication.

Table 2: Repository engagement (to March 2014)

\begin{tabular}{|l|c|c|c|c|c|c|}
\hline \multicolumn{1}{|c|}{ Library Repository } & $\mathbf{2 0 0 9}$ & $\mathbf{2 0 1 0}$ & $\mathbf{2 0 1 1}$ & $\mathbf{2 0 1 2}$ & $\mathbf{2 0 1 3}$ & $\mathbf{2 0 1 4}$ YTD \\
\hline Total records & 12,357 & 24,179 & 24,403 & 29,427 & 30,777 & 31,044 \\
\hline Full text items (open access) & 492 & 972 & 1,753 & 2,411 & 3,222 & 3,394 \\
\hline Percentage (open access) & 4 & 4 & 7.2 & 8.2 & 10.5 & 10.9 \\
\hline
\end{tabular}

\section{Case 2: Repositioning a curriculum development resource from iTunes to OER}

The university's intellectual property policy supports academics to make their teaching materials publicly accessible, yet resources created for teaching and learning are typically placed in the enterprise LMS, hence not visible to search functions externally or within the university. Exceptions to this trend are instances in which academics and resource creators place teaching materials in the public domain, using blogs, YouTube, Vimeo, Prezi, Wikimedia and other platforms, sometimes under Creative Commons licences. These initiatives have been limited to a few specific units, projects or individuals.

An initiative that has had a much wider scope is the distribution of university educational content via iTunes U. This project, initiated in April 2008, aimed to make selected teaching materials accessible to the public. By January 2014, the university had 98 collections and 26 courses on iTunes U, generating more than 17 million downloads of teaching materials by both public users and enrolled students. Content includes audio recordings, videos, PDFs and other digital materials, including seminars given by university staff and visiting scholars. For example, the Language Diversity collection is composed of fortnightly seminar recordings hosted by the university's Centre for Research on Language Diversity (CRLD). While the seminar series typically attracts 12-20 face-to-face audience members, podcasts and PDFs of individual seminars in the university's iTunes $U$ collection register 3,000 downloads. The distribution of learning resources in the public domain via the iTunes $U$ platform has greatly increased accessibility and access to the university's educational content.

However, while iTunes $U$ has greatly increased public access to the university's educational resources, it has generally not been in ways that are compatible with OEP. Access and openness to resources in iTunes $U$ is limited by copyright regulations, licensing, publishing practices and policy. Default licensing for materials in iTunes $U$ courses and collections are marked "All rights reserved", despite six open licensing options that are available. These materials are hosted on the central marketing server and are distributed via an RSS feed which is linked to the iTunes $U$ interface, thus the content of the collections can be viewed on any computer with iTunes software. Moreover, the iTunes $U$ course folders have additional materials, such as questions for discussion or recommendations for further reading, and these are accessible only on certain Apple mobile devices, including iPads, iPods and iPhones. Not only does this greatly limit accessibility, it potentially contravenes the Australian Education Accessibility Act, which specifies that such material be accessible to enrolled students through an alternative method.

Recent initiatives have attempted to address these restrictions in the institutional use of iTunes $U$ by repositioning the platform in a way that is compatible with and enhances OEP. In 2013, the university's Open Education Work- 
ing Group began a process of building OEP into iTunes $U$ practice and policy, with small but significant changes made to the Curriculum Development collection in iTunes U. This collection of podcasts was assembled from LaTrobe academics and visiting scholars on educational design and policy, and recordings of professional development seminars have been reaching wider audiences since 2009, when the collection was established on iTunes U. In late 2013, the podcast of a seminar by visiting scholar Professor Marcia Devlin on Inclusive Teaching for Low SES Background Students was uploaded to the library digital repository rather than the central marketing server. With the permission of the presenter, a Creative Commons Attribution 3.0 Australia licence was applied to the podcast and slides, with both uploaded to the digital repository as OER (Figure 4). The web link from the repository was then linked to the iTunes $U$ collection with the same Creative Commons licence (see Figure 5).

Figure 4. Inclusive Teaching OER

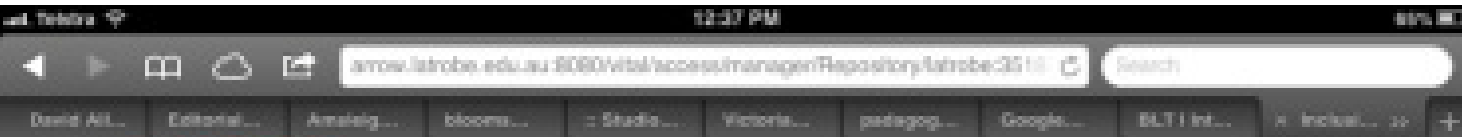

\section{a. LA TROBE \\ UNIVERSITY}

\section{Research Online}

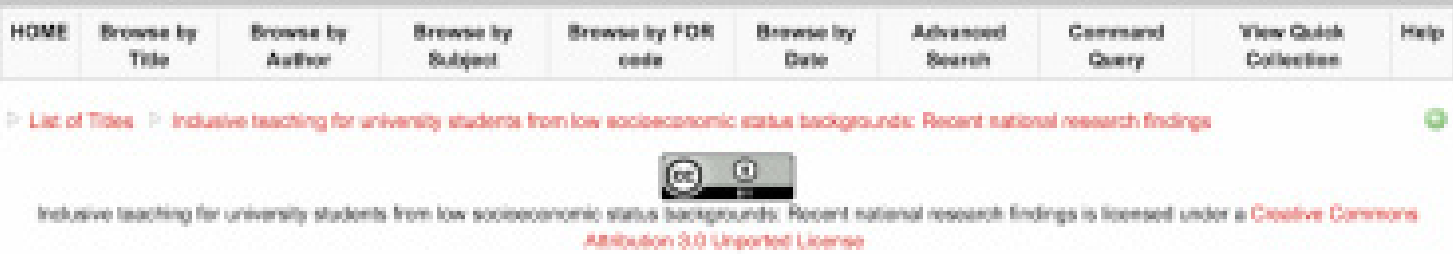

\begin{tabular}{|c|c|c|}
\hline For Acenes & Deaciption & Fornut \\
\hline Gosnmasures & MS Powerpein: phosertanen - (T 2) NE) & application/ru-powerpoint \\
\hline Goth mescuse & Mudo pvesertition - (97.4 Ma) & vetrpeg \\
\hline
\end{tabular}

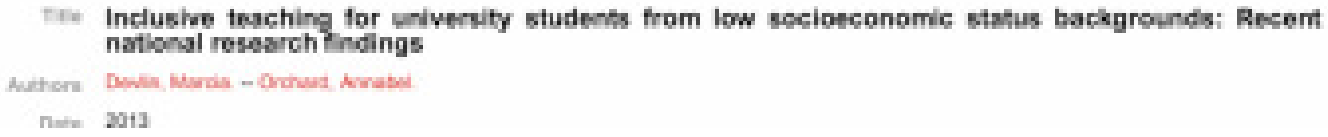

Locating the Inclusive Teaching OER in the digital repository enabled access from any computer or device without the need for proprietary software. In February 2014, the podcast was accessed directly through the digital repository 71 times by 37 visitors, and also downloaded 255 times via iTunes U. Linking the podcast to the existing Curriculum Development collection in iTunes $U$ reached a wider audience. Both platforms have an open Creative Commons licence hence materials can be used, adapted and redistributed. Offering the resource through iTunes $U$, as well as the open repository, has increased access to the resource. 
This example was an outcome of the arrangement between the university and iTunes $\mathrm{U}$ : an instance of a productive partnership mentioned above. Thus, existing university systems can be modified to improve access, accessibility and openness of educational resources.

Figure 5. La Trobe University iTunes U Curriculum Development collection

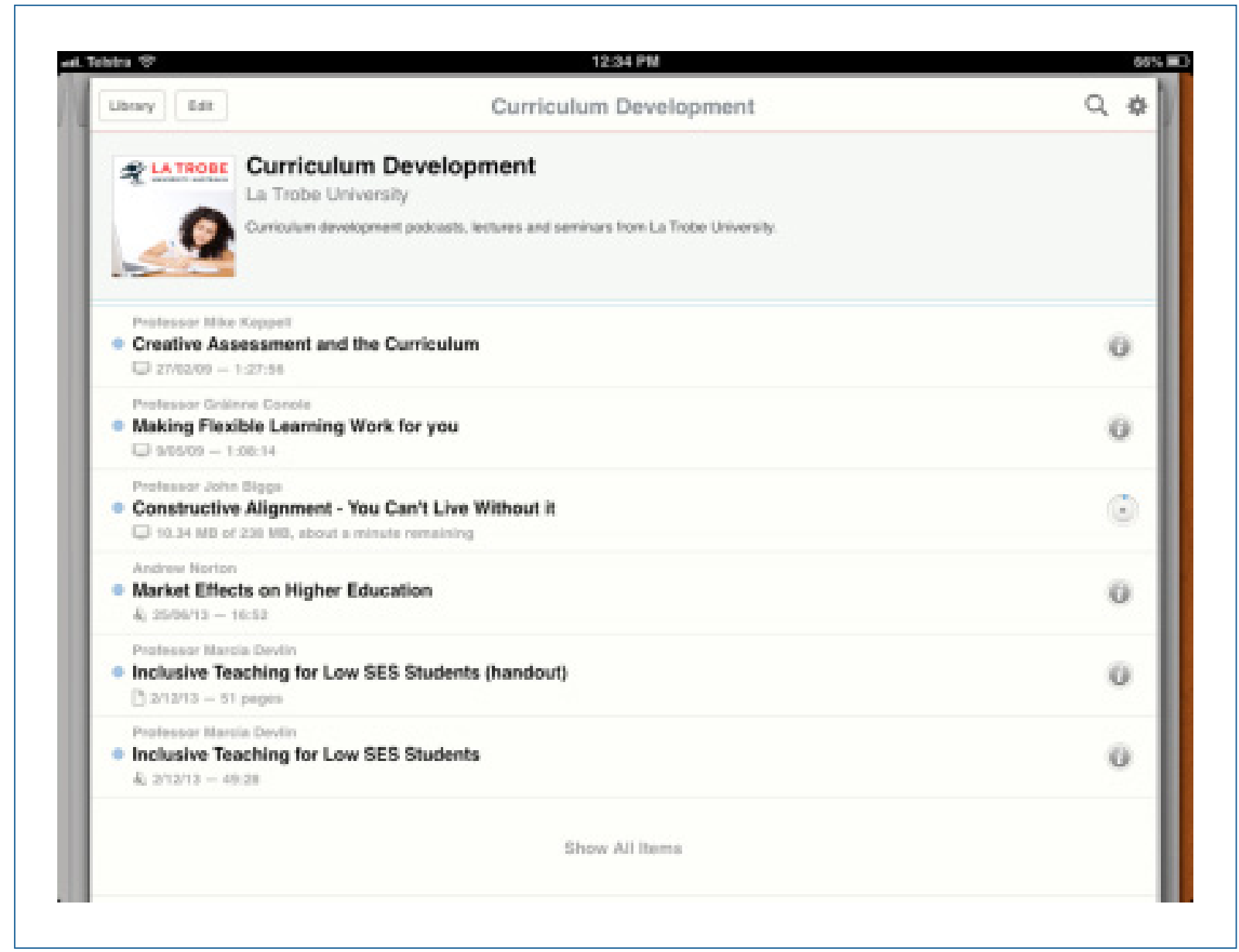

Case 3: Duelling platforms: The evolution of Indigenous and Intercultural Health into an OER

The Faculty of Health Sciences at La Trobe University includes a vast array of disciplines, programs, courses and units. However, an external review found a lack of Indigenous focused strategy and curriculum. A subsequent audit of the 2013 university handbook conducted by the author supported this observation and found that across the entire university there were a total of 16 units with either 'Aboriginal' or 'Indigenous' in the title, with none in Health Sciences.

This presented an opportunity to address this lack in the faculty's offerings. Extensive discussion with course and curriculum managers, however, revealed divergent responses: on the one hand, there were longstanding pockets of Indigenous-related research, service delivery and some teaching activity. Though largely disconnected, 
they reflected a local commitment and recognition by some staff of the need to prepare health and social care professionals to work effectively with Indigenous people. They saw it as their responsibility to help 'close the gap' between the health and wellbeing of Indigenous and mainstream populations.

Other discussions revealed starkcontrasts. Typical statements were repeated that resembled thefollowing:"I'm very supportive of improving Indigenous health. However, very few of our graduates will ever see an Indigenous patient."

Surveys were developed and circulated to all faculty staff and students to gain an indication of the level of support and perceived professional relevance for Indigenous curricula. In summary, nearly 200 respondents from more than 24 disciplines expressed unequivocal support for the development of a range of Indigenous engagement strategies and programs. In particular, there was clear support (mean agreement of 4 or above out of 5) for at least one new core unit that included an explicit focus on Indigenous health and social care. The turning point came in the form of new mandated curriculum requirements in the national nursing program accreditation body (Australian Nursing \& Midwifery Accreditation Council, ANMAC). These stipulated that the core nursing program"specifically address Aboriginal and Torres Strait Islander peoples' history, health, wellness and culture"2. The School of Nursing committed to the development of the new unit by funding the services of an external, well-qualified Indigenous health professional and academic.

The unit Indigenous and Intercultural Health (2013) was subsequently developed on the open educational platform, Wikiversity, for the following reasons:

Development required the collaboration of a range of physically and institutionally dispersed stakeholders, including participants who were not university staff and could not access the university LMS and other systems. Hence, both development and the actual resources produced needed to be open, usable and modifiable by the communities and health and social care agencies local to each of La Trobe's campuses. Consequently, access was not restricted to staff and enrolled students, and it continued after completion to enable ongoing partnership with practitioners. Open access for ongoing collaboration with the community partner teachers was seen as being integral to delivery (Nguyen \& Gardiner, 2008)

Institutional unit development and templates were complicated and onerous to manage, and linguistically difficult to access for the development partners. In contrast, the Wikiversity format is relatively simple, stable and universally accessible. By developing the unit primarily on Wikiversity, it was possible to include more than one'voice', in this case, that of an Indigenous person speaking from and to her own communities as well as the 'whitestream'. This resulted in the central, Indigenous focused module to speak directly to and with Indigenous perspectives, a significant step towards making Indigenous health sciences students feel better accommodated in the course and institution (Sullivan \& Sharman, 2011)

Historically, Australian and other Indigenous people have been the subject of 'white man's study' for centuries. This has often led to the objectification and appropriation of Indigenous knowledge, with little benefit returning to those being researched or studied (Morgan, 2003). Wikiversity allowed the unit developers to work with and for interested stakeholders, with a level of transparency and accountability not possible with traditional platforms. This openness was seen as a way of partially addressing some of the understandable suspicion and resistance to participation in academic work (Figure 6).

Some of these benefits have been slow to be realised; however, there was 'in principle' acceptance of the open platform, expressed through widely sourced input into the shape and balance of content. The open platform also

2. ANMAC Registered Nurse Accreditation Standards p15

RUSC VOL. 11 No 3 | Universitat Oberta de Catalunya and University of New England | Barcelona, July 2014 @ (a) John Hannon, Simon Huggard, Annabel Orchard and Nick Stone | @ 2014 by FUOC | OER in practice: Organisational change by bootstrapping 
enabled a partnership model to evolve, in which one of the State's peak Indigenous health organisations has not only approved content within its purview, but some of its staff volunteered their time and ideas to collaborate in the development of pivotal case study video materials. These resources, along with linked learning activities, have now become part of their own training programs. Another, mainstream, large rural health organisation has also requested use of these resources for its community-based training programs. These and other resources are co-branded resulting in a dual custodianship by representatives of both agencies, covered overall with a Creative Commons 3.0 licence.

There remained one major obstacle to a peaceful co-existence between the two cultures: LMS constraints and Wikiversity. Managing the development, maintenance, updating and review of such a unit is challenge enough on one platform. Trying to synchronise two quite different platforms seemed difficult and resource intensive.

A solution eventually emerged through feeding the live Wikiversity version into the LMS page. Changes made to the 'master' version are almost immediately reflected within the LMS. Students access the Wiki version for a simple presentation of content and assessment requirements, while using the LMS to complete tasks and engage in collaboration with secure access to the cumulative achievement and attendance records. Thus, the LMS culture is able to embrace the Wiki version and automatically remain up to date with its open counterpart. (Figure 7).

The unit will be trialled in 2014 with a cohort of students who will gain credit on completion. Monitoring and evaluation of this trial will be essential to ensure necessary responsive changes, especially in managing duelling platforms. This model of community engagement and partnership holds considerable potential for future curricula and is a pragmatic response to perennial issues arising from competing information systems and philosophies for community accountability and engagement. 


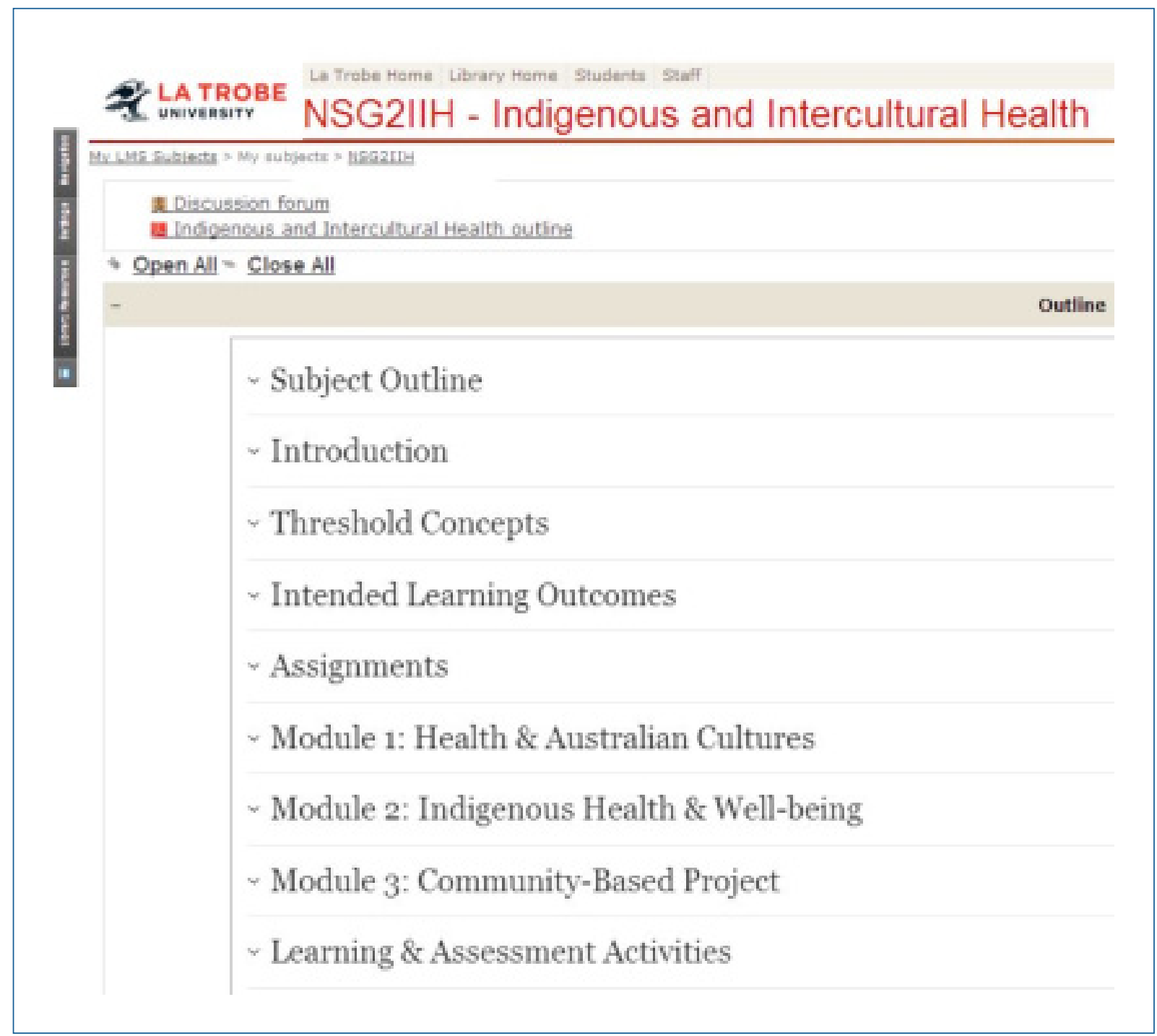

\section{Concluding remarks: Embedding OEP}

The growth and reach of OER worldwide has been extensive and also uneven, and adoption in universities in Australia has been slow (Bossu et al., 2012). The case studies above confirm that key obstacles to adoption include the difficulties translating established OER into OEP, and the resistance from competing practices embedded throughout the university: in teaching practices, learning technology systems, organisational processes, and the needs of specific student cohorts. The issue raised in this paper concerned the potential for productive innovations in OEP to initiate institutional change, producing effects beyond the local case, and potentially to establish a "culture of innovation".

The first two cases described an adaptation of a technological arrangement already embedded in the university. The library modified its well-established digital repository and extended its curation of open research outputs to encompass OER. Usage data indicated modest uptake at an early stage, and the developers of the repository 
commented that a communication strategy to teaching academics was necessary to increase awareness and adoption.

The library repository also provided an alternative location for resources published in the university's successful iTunes $U$ project. By managing a process of assigning open licences, curricula already available to a vast audience via iTunes $U$ can be available as OER through the repository. An OEP process was initiated that built upon supportive university policies and benefited from the existing effective track record of iTunes $U$.

In the third case, OER took the form of the unit Indigenous and Intercultural Health, in a process that established connections beyond the institution through an open Wikiversity location. Curriculum development in Wikiversity was then reflected in the LMS, and this coupling of two platforms made curriculum work more sustainable. The standard LMS arrangements were not disrupted, rather a "workaround" or unofficial system (Brown, 2013) was deployed to achieve curriculum project goals.

Significantly, the Wikiversity case demonstrated an inclusive community partnership that did not exclude participants through closed university systems and staff/student logins. This engagement involved representative Indigenous organisations and was an important development of a more sustainable and enduring stakeholder engagement in a curriculum that persisted beyond a semester length.

The successful institutional innovation demonstrated in the iTunes $U$ and Wikiversity projects exemplifies Gunn's (2014) "productive partnerships", where external connections are negotiated that are mutually beneficial, with the goal of producing sustainable outcomes. These cases of institutional initiatives of putting OER into practice demonstrate two aspects of OEP: each case instantiates a form of open education that is tailored to particular teaching and learning goals, and each case established connections with other entities related to OER - whether partners, policies, technology systems, repositories, or curricula, from inside or outside the university. In the iTunes U case, OEP built upon the existing Curriculum Development collection, and in the Wikiversity case, course development occurred in concert with the indigenous community and with associated public health professionals also developing on Wikiversity. The OEP initiatives, therefore, adapted to and augmented existing social and technical arrangements, in effect bootstrapping the institution by establishing new practices that can be adapted or deployed in other settings.

Bootstrapping, in Bardini's (2000) sense of the adaptive, reciprocal, social-technical movements within the organisation, was expressed in these cases of OEP in terms of Gunn's (2014) "productive partnerships" and, therefore, were capable of supporting the cultures of innovation necessary for local initiatives to shift from marginal to sustainable institutional practice. If bootstrapping organisational change is to occur through local OER initiatives activating institutional OEP, it is critical that new arrangements are established and nurtured with diverse socialtechnical entities, including participants, procedures, policies and technologies alike.

\section{References}

Bardini, T. (2000). Bootstrapping: Douglas Engelbart, Coevolution, and the Origins of Personal Computing. Stanford, CA: Stanford University Press.

Bossu, C., Brown, M., \& Bull, D. (2012). Do Open Educational Resources represent additional challenges or advantages to the current climate of change in the Australian higher education sector? ascilite 2012 Conference Proceedings, Wellington, 124-132. Retrieved from http://www.ascilite2012.org/images/custom/bossu,_carina_-_do_open.pdf 
Brown, S. (2013) Large-scale innovation and change in UK higher education. Research in Learning Technology, 21.

Conole, G. (2012) Fostering social inclusion through open educational resources (OER). Distance Education, 33(2), 131-134. doi http://dx.doi.org/10.1080/01587919.2012.700563

Gunn, C. (2014). Innovators and Institutions Working as Partners on Sustainable Change. In M. Gosper \& D. Ifenthaler, Curriculum Models for the 21st Century: Using Learning Technologies in Higher Education (pp. 389-406). New York, NY: Springer. doi http://dx.doi.org/10.1007/978-1-4614-7366-4_20

Hannon, J. (2013) Incommensurate practices: Sociomaterial entanglements of learning technology implementation, Journal of Computer Assisted Learning 29 (2), pp. 168-178. doi http://dx.doi.org/10.1111/j.1365-2729.2012.00480.x Hannon, J., Bisset, D., Blackall, L., Huggard, S., Jelley, R., Jones, M., Orchard, A. \& Sadler, R. (2013) Accessible, reusable and participatory: Initiating open education practices. In M. Gosper, J. Hedberg, H. Carter (Eds.) Electric Dreams. Proceedings ascilite Sydney 2013. (pp. 362-372). Retrieved from http://www.ascilite.org.au/conferences/sydney13/ program/papers/Hannon.pdf

Higher Education Research Data Collection (HERDC) (2014). Department of Education, Australian Government. Retrieved from http://education.gov.au/higher-education-research-data-collection

Indigenous and Intercultural Health (2013). Wikiversity. Retrieved from http://en.wikiversity.org/wiki/Indigenous_ and_Intercultural_Health

Johnson, L., Adams Becker, S., Cummins, M., Estrada, V., Freeman, A., \& Ludgate, H. (2013). NMC Horizon Report 2013 Higher Education Edition. Austin, TX: The New Media Consortium. Retrieved from http://www.nmc.org/ publications/2013-horizon-report-higher-ed

Lane, L. (2009). Insidious pedagogy: How course management systems affect teaching. First Monday, 14(10). doi http://dx.doi.org/10.5210/fm.v14i10.2530

McGreal, R., Kinuthia, W., \& Marshall, S. (2013). Editorial. Open Educational Resources: Opening Access to Knowledge [Special issue]. The International Review of Research in Open and Distance Learning, 14(2), i-iv. Retrieved from http:// www.irrodl.org/index.php/irrodl/article/view/1549/2501

McKerlich, R., Ives, C., \& McGreal, R. (2013). Measuring use and creation of open educational resources in higher education. The International Review of Research in Open and Distance Learning, 14(4). Retrieved from http://www. irrodl.org/index.php/irrodl/article/view/1573

Morgan, D. L. (2003). Appropriation, Appreciation, Accommodation: Indigenous Wisdoms and Knowledge in Higher Education. International Review of Education, 49(1-2), 35-49. doi http://dx.doi.org/10.1023/A:1022937003545

Neary, M. \& Winn, J. (2009). The student as producer: reinventing the student experience in higher education. The future of higher education: policy, pedagogy and the student experience (pp. 192-210). London: Continuum. Retrieved from http://eprints.lincoln.ac.uk/1675/

Nguyen, H. T., \& Gardiner, A. (2008) Indigenous community members as teachers of indigenous health. Australian Family Physician, 37(12), 1019-1021.

OPAL (2011). Beyond OER: Shifting Focus from Resources to Practices: The OPAL Report 2011. Open Educational Quality Initiative. Retrieved from http://www.educause.edu/Resources/BeyondOERShiftingFocustoOpenEd/224619

Pegler, C. (2013). The Influence of Open Resources on Design Practice. In H. Beetham \& R. Sharpe (Eds.), Rethinking Pedagogy for a Digital Age: Designing for 21st Century Learning (pp. 306-333). New York: Taylor \& Francis.

Rogers, E. (2003). Diffusion of innovations (5th ed.). New York: Free Press.

Schon, D. (1995). The Reflective Practitioner: How professionals Think in Action. Aldershot, England: Arena (originally published 1983, New York: Basic Books). 
Stake, R. (2008). Qualitative Case Studies. In N. Denzin \& Y. Lincoln (Eds.), Strategies of Qualitative Inquiry (3rd ed., pp. 119-149). Thousand Oaks, CA: Sage.

Sullivan, K. A., \& Sharman, R. (2011). A practical method of embedding a traditional Indigenous perspective in tertiary training for future health practitioners. Australian Aboriginal Studies, 1, 197-201.

Wellen, R. (2013). Open access, megajournals, and MOOCs: on the political economy of academic unbundling. Sage Open, 3(4). doi http://dx.doi.org/10.1177/2158244013507271

Weller, M. (2011). The Digital Scholar: How Technology is Transforming Scholarly Practice. London: Bloomsbury Publishing.

Wiley, D., \& Gurrell, S. (2009). A decade of development... Open Learning: The Journal of Open, Distance and e-Learning, 24(1), 11-21. doi http://dx.doi.org/10.1080/02680510802627746

Yin, R. (2009). Case Study Research: Design and Methods (4th ed.). Thousand Oaks, CA: Sage Publications.

\section{About the authors}

John Hannon

j.hannon@latrobe.edu.au

Senior Lecturer, Learning and Teaching at La Trobe, La Trobe University, Australia

Dr John Hannon is a senior lecturer in Learning and Teaching at La Trobe University. He has a key role in the university's strategy for developing innovative and effective pedagogical approaches for online and blended learning. He teaches in the field of higher education teaching and learning, and his research focuses on transitions in academic and professional practice, including the use of digital technologies in learning contexts, learning in the spaces of Web 2.0, and the use of open educational resources and practices. His published research investigates issues for universities with educational technologies, professional practice, open education and intercultural communication.

La Trobe University

Melbourne VIC 3086

Australia

\section{Simon Huggard}

s.huggard@latrobe.edu.au

Digital Infrastructure Manager, Borchardt Library, La Trobe University, Australia

Simon Huggard has been the manager of the Digital Infrastructure team in the library at La Trobe University since 2012. He manages a team of staff responsible for the library's Research Online repository, search, linking and discovery systems, library management system, copyright and audio-visual requests. Simon has written many articles and presentations relating to library systems and information access, and is a strong advocate for open access, Creative Commons licences and the provision of smart systems for accessing digital library content. Simon previously held positions at the State Library of Victoria and Monash University, Australia, where he worked closely on system implementation, customised web and application interfaces, usability and software development.

La Trobe University

Melbourne VIC 3086

Australia

RUSC VOL. 11 No 3 | Universitat Oberta de Catalunya and University of New England | Barcelona, July 2014 


\author{
Annabel Orchard \\ annabel.orchard@monash.edu \\ Educational Designer, Better Learning and Teaching Team, Office of the Pro-Vice Chancellor (Learning and Teaching), \\ Monash University, Australia
}

Annabel Orchard has recently moved to Monash University after three years at LaTrobe University, Australia. She has worked extensively in the innovation and development of multimedia for learning enhancement, and also in tertiary teaching, and curriculum design and development. Annabel has developed eLearning resources for the University of Melbourne, La Trobe University, the ABC, the lan Potter Gallery, the Australian Department of Employment, Education and Training, and others. Recent projects at LaTrobe included coordinating the Mobile Learning Devices Pilot Project, developing digitised resources for flexible delivery via iTunes $U$, and participating in the Open Education Working Group. Annabel has taught Classics since 2000 at the University of Melbourne, Monash University and LaTrobe University.

Monash University

Wellington Rd, Clayton VIC 3800

Australia

\title{
Nick Stonen.
}

stone@latrobe.edu.au

Intercultural and Evaluation Consultant, La Trobe University, Australia

Nick Stone has worked as a researcher, lecturer and consultant at La Trobe, Melbourne, Deakin, Monash, RMIT and other universities in Australia. He works with the Australian Culture Resource Centre to prepare Defence Force personnel in 'Cultural Intelligence' for overseas missions. He has worked across different sectors, mainly in studies and practice of management, education and health. Over the past 14 years, he has specialised in teaching and research on intercultural learning and development across a range of disciplines. Nick's recent work includes teaching 'Intercultural Effectiveness' and 'Cross-Cultural Management', evaluating and refining major reforms and innovations in health sciences education, establishing a Faculty Indigenous Engagement Strategy, and developing a new multidisciplinary subject on 'Indigenous and Intercultural Health'. Nick's near-complete PhD focuses on 'Assessing Intercultural Effectiveness in Management Learning and Practice'.

La Trobe University

Melbourne VIC 3086

Australia

The texts published in this journal are - unless indicated otherwise - covered by the Creative Commons Spain Attribution 3.0 licence. You may copy, distribute, transmit and adapt the work, provided you attribute it (authorship, journal name, publisher) in the manner specified by the author(s) or licensor(s). The full text of the licence can be consulted here: <http://creativecommons.org/licenses/by/3.0/es/deed.en>

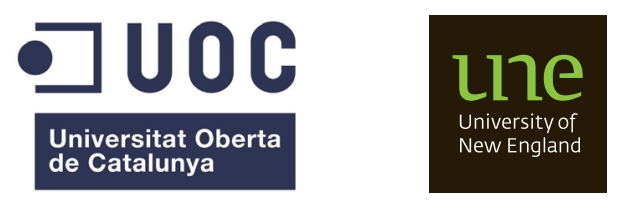

